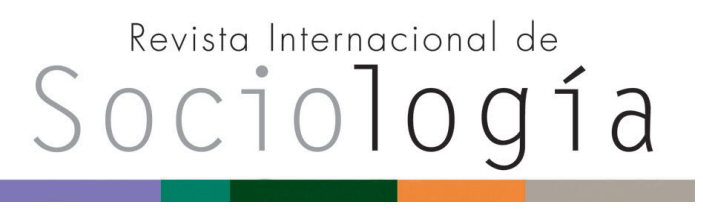

Revista Internacional de Sociología RIS vol. 77 (3), e134, julio-septiembre, 2019, ISSN-L:0034-9712 https://doi.org/10.3989/ris.2019.77.3.18.031

\section{POBRES Y ELECTORES. UNIVERSALIDAD Y FOCALIZACIÓN DE LA POLÍTICA SOCIAL EN LA REPÚBLICA DOMINICANA 2006-2012}

POOR AND VOTERS.

UNIVERSALISM AND SELECTIVITY THROUGH SOCIAL POLICY IN DOMINICAN REPUBLIC 2006-2012

\author{
ANA BELÉn BENITO SÁNCHEZ \\ Centro de Estudios Políticos y Constitucionales (CEPC). Madrid. España \\ ana.benito@cepc.es \\ https://orcid.org/0000-0003-0402-5419
}

Cómo citar este artículo / Citation: Benito Sánchez, A. B. 2019. "Pobres y electores. Universalidad y focalización de la política social en la República Dominicana 2006-2012". Revista Internacional de Sociología 77(3):e134. https://doi.org/10.3989/ris.2019.77.3.18.031
Copyright: @ 2019 CSIC. Este es un artículo de acceso abierto distribuido bajo los términos de la licencia de uso y distribución Creative Commons Reconocimiento 4.0 Internacional (CC BY 4.0).

Recibido: 19/02/2018. Aceptado: 17/01/2019.

Publicado online: 24/09/2019

\section{Abstract}

This work analyzes the strategic use of social public ex-penditure in Dominican Republic by comparing social assistance and social security budgets for the period between 2006 and 2012. The data reveal the potential partisan use of social assistance in time of elections and the bifurcation of the social protection regimes.

\section{KEYWORDS}

Conditional Cash Transfers; Elections; Latin America; Previsional Protection; Public Expenditure. 


\section{INTRODUCCIÓN}

Las medidas de ajuste que los organismos internacionales impusieron a los gobiernos latinoamericanos en los años noventa reorientaron la política social hacia soluciones monetarias compensatorias de responsabilidad individual, ajenas a la desmercantilización de la provisión y el riesgo compartido keynesianos. El impacto de estas nuevas herramientas en la reducción de la pobreza extrema -entre las que despuntaron programas de transferencias condicionadas (PTC) como «Bolsa Familia» en Brasil o «Progresa» en México- favoreció su extensión y se implementaron en la mayoría de los gobiernos progresistas del giro a la izquierda que vivió la región. A pesar de su éxito, estas transferencias han sido cuestionadas por el uso estratégico, la cooptación clientelar de sus beneficiarios y la institucionalización de la desigualdad.

Para comprobar si la protección de los grupos vulnerables se ve afectada por la dinámica electoral, este trabajo analiza el uso estratégico del gasto social previsional de vocación universal y compensatorio focalizado en la República Dominicana en el periodo 2006-2012. Aunque en estos años el país experimentó un importante crecimiento económico, fueron escasos los avances redistributivos: un coeficiente de Gini similar al de la década de los ochenta y tasas de pobreza e indigencia del $38,7 \%$ y $18,9 \%$, respectivamente (CEPAL 2012: 87). Las asignaciones monetarias selectivas coexisten con programas de corte universal, por lo que el predominio de estos últimos sobre aquellas es considerado indicador de calidad del gasto público en democracia (Filgueira 1998; Hevia 2010).

Con este objetivo, el artículo se organiza en cuatro secciones. En primer lugar, se examina la literatura sobre patrones de gasto público y política distributiva como estrategia movilizadora y de recompensa para conquistar el voto en escenarios de competición clientelar. En segundo lugar, se presenta el panorama de la protección social en América Latina y las particularidades del caso dominicano. La ejecución mensual del gasto social y la contratación de empleados para implementar los programas asistenciales en la República Dominicana confirman el potencial politizador de las transferencias monetarias en época electoral, así como la bifurcación interesada de los regímenes de protección social. A partir de los hallazgos, en las conclusiones se reflexiona sobre los efectos en la cohesión social de este modelo neoliberal de bienestar fragmentado y residual.

\section{DISCUSIÓN TEÓRICA E HIPÓTESIS}

La aparición de los programas de transferencias condicionadas para combatir la pobreza marcó un punto de inflexión en la fisionomía de los "proto estados" del bienestar latinoamericanos de base estatal proteccionista, productivista y familiarista (Martínez 2007; Carrera y Muñoz 2009; Gough y Therborn 2010). Desde entonces, han sido muy diferentes las estrategias para hacer converger estas nuevas herramientas focalizadas compensatorias con las previsionales de vocación universal. Para los más críticos, la institucionalización de los PTC estaría fragmentando el sistema de bienestar, convirtiéndolo en residual y de excepción, entorpeciendo el impulso expansivo de las reformas del año 2000 (Arza 2013; Antía 2013; Fraser 2012; Lavinas 2013). Desde mediados de los noventa, el $40 \%$ de los hogares latinoamericanos ha ascendido de clase socioeconómica gracias a estos subsidios, pero no han pasado a formar parte de la clase media, sino de un nuevo grupo que los analistas denominan "la clase de los vulnerables". Este grupo constituye la categoría social más numerosa y en la que, en 2012, se ubicaba el $38 \%$ de los latinoamericanos (Ferreira et al. 2013). Los nuevos hogares de "casi pobres" tienen una probabilidad relativamente alta de vivir episodios de pobreza en el futuro, y no están cubiertos frente a los efectos adversos de los ciclos económicos y los riesgos comunes de la vida.

A las críticas por la eficacia relativa de los PTC se suman aquellas que denuncian que la personalización de su concesión inhibe la acción colectiva, refuerza los roles de género (Cibecchi 2008) y el estigma del "mal pobre" (Baraibar 2015). La condicionalidad de este tipo de ayudas traslada la responsabilidad por la situación individual de necesidad al propio ciudadano que la padece, desconectándola de las desigualdades estructurales del mercado de trabajo o la educación (Stampini y Tornarolli 2012; Lavinas 2013), de los sistemas fiscales regresivos (Amarante y Jiménez 2016) o de la captura extractiva del Estado (Acemoglu y Robinson 2012). Este proceso de asistencialización de la política social, alejado del modelo universalista redistributivo basado en derechos, transitaría del seguro social -colectivización de los riesgos de la vida- a la tarjeta de asignación individualizada; del derecho justiciable a la ayuda o el favor, y del ejercicio ciudadano de derechos y deberes a la condicionalidad con premios y castigos (Andrenacci 2009; Gilbert 2004). El mayor protagonismo de los programas monetarios compensatorios frente a los sistemas previsionales estaría legitimando la desresponsabilización del Estado con el bienestar ciudadano, reconduciéndolo a un acto de voluntarismo no sujeto al control de legalidad o de la justicia social (Adelantado y Scherer 2008). En este modelo de monetarización de la provisión de servicios se otorgan al mercado y al crecimiento económico un rol determinante en la incorporación social de los grupos vulnerables, a pesar de que la mejora en los salarios, la creación de empleo y las políticas universalistas han demostrado ser los factores con mayor impacto en la reducción de la pobreza y la inequidad (Therborn 2011; Lavinas 2012; Huber y Stephens 2012). 
Los trabajos sobre la utilización partidista y electoral de los beneficios sociales selectivos en países emergentes (Scott 2001; Calvo y Murillo 2004; Weitz-Shapiro 2014) han diversificado la agenda de investigación acerca de las estrategias distributivas en democracia (Levitt and Snyder 1995; Alesina, Danninger y Rostagno 1999; Berry, Burden y Howell 2010). Si bien algunos autores han calificado de innovación democrática la gestión descentralizada, transversal y participativa de los PTC (De Lima 2017), así como sus efectos redistributivos (Mares y Carnes 2009; Stokes et al. 2013), no faltan voces que cuestionan su impronta populista, clientelar y su efecto en la institucionalización de la desigualdad (Schady 2000; Magaloni 2006; Hevia 2010; Takahashi 2007; Hawkins 2010; Weyland 2013). En la identificación de la manipulación política del gasto público, la clasificación de Dixit y Londregan (1996) permite ubicar los escenarios propicios para la redistribución programática de bienes generales y la redistribución táctica de bienes particulares. La redistribución programática es reflejo de las creencias ideológicas acerca de la igualdad y se lleva a cabo a través de una política impositiva y un estado del bienestar de vocación generalizada o universal. Se caracteriza por su ejecución estable en el tiempo y solo cambia cuando hay algún viraje ideológico en la sociedad. Por el contrario, la redistribución táctica sigue una dinámica propia y autónoma en la asignación de beneficios particulares, motivada por la competición política y la maximización del rédito electoral (Dixit y Londregan 1996:1132).

En escenarios altamente competitivos, ganar o perder puede ser cuestión de un pequeño cambio en la estrategia de distribución de beneficios selectivos (subsidios, patronazgo, exenciones industriales...) a ciertos grupos de interés. El trabajo de De la O (2013) sobre el impacto del subsidio mexicano «Progresa» demuestra que el efecto electoral de las asignaciones selectivas se manifiesta tanto en términos de incremento de la participación como en el respaldo al partido oficialista de turno. En contextos de escasa vinculación ideológica y programática, los grupos con menor nivel de renta cuya utilidad marginal de ingreso es mayor estarán más dispuestos a comprometer sus preferencias políticas si reciben este tipo de beneficios selectivos. Frente a esta estrategia de gasto particularista swing voter, que beneficia a moderados desleales e indecisos, en electorados polarizados y fuertes afinidades partidistas los actores políticos optarán por favorecer a aquellos votantes duros core support cuyos intereses de grupo sea más relevantes en la liza política (Dixit y Longredan 1996: 1144). Ante contextos de competencia clientelar, la academia se encuentra dividida, en la identificación del criterio de selección de beneficiarios, entre quienes argumentan una asignación que premia a los votantes fieles (Nitcher 2008; Ansolabehere y Snyder 2003; De la Calle 2005) y aquellos que apuntan a una asignación para persuadir a votantes opositores e indecisos (Stokes 2005; Weitz-Shapiro 2006). En una posición intermedia, trabajos como el de Kramon y Posner (2013) o Rosas y Hawkins (2008) muestran un modelo de concesión estratégica de beneficios mixto: bienes privados para movilizar a votantes fieles y bienes públicos para persuadir a opositores moderados.

La selección de beneficiarios que disfrutarán de los bienes controlados por el partido del gobierno es posible gracias al poder de decisión y manipulación del agente (Dowding 1994; Piattoni 2001; Maiz 2005) y a un escenario de oportunidad regido por la flexibilidad presupuestaria y la debilidad de la accountability horizontal que caracteriza las democracias delegativas (O’Donnell 1994). Como demostraran Medina y Stokes (2007), en ausencia de políticas fiscales redistributivas y cuando el partido oficialista controla el acceso a los recursos, los partidos opositores que oferten bienes universales tienen pocas opciones de llegar al poder, a pesar de ser la opción más inclusiva y óptima en el largo plazo. La desconfianza y la desigualdad en el acceso a los recursos desincentivan la cooperación, en una interacción similar al "dilema del prisionero", por lo que el bien individual será el ofrecido por los agentes y el preferido por el principal (Gambetta 1988; Shefner 2001). La implementación de políticas universales conllevaría un aumento de impuestos para financiar los bienes antes distribuidos y disfrutados de manera selectiva. Por esta razón, el partido oficialista se mostrará contrario a la subida de impuestos, no por un componente ideológico, sino porque no conseguirá la reelección (Medina y Stokes 2007: 75).

En el caso de los clientes, la mejor opción es votar al partido del patrón, ya que tendrían asegurado el disfrute del bien universal ofertado por el partido programático si este alcanzara el poder. Pero si el partido del patrón gana, quedarían excluidos del disfrute del bien cuando la red de monitoreo constate su deslealtad. En contextos de desarrollo económico alto, como Japón (Scheiner 2007) e intermedio, como Argentina (Levitsky 2007), los políticos optan por un menú diversificado de políticas particularistas y programáticas, condicionados por las limitaciones presupuestarias y el mayor rechazo de las rentas medias a las prácticas clientelares. En los países de bajo nivel de desarrollo, la política clientelar es la mejor opción, dado el bajo coste de los votantes marginales o "clientes pobres pero ricos en votos" (Kitschelt y Wilkinson 2007).

El objetivo de este artículo es identificar los patrones de distribución del gasto social en la República Dominicana y evidenciar su uso estratégico en el marco de las teorías sobre la manipulación política del gasto público. Las transferencias monetarias condicionadas se implementaron en el país bajo la administración de Leonel Fernández (2004-2008). 
En 2004, el Partido de la Liberación Dominicana (PLD) conquistaba el Ejecutivo a Hipólito Mejía, del opositor Partido de la Revolucionario Dominicano (PRD), un año después de la crisis financiera que colapsó la economía y elevó de forma dramática los niveles de pobreza del país ${ }^{1}$. En 2006, el PLD revalidaba su victoria en las congresuales, consiguiendo por primera vez en su historia la mayoría en el Legislativo. Desde entonces, el PLD se ha consolidado como partido predominante y ha logrado cooptar en 2016 al principal partido de la oposición como socio de gobierno. La competitividad entre las dos principales fuerzas políticas en estos años ha pasado de un $15,3 \%$ en 2006 a un escaso $3,2 \%$ en 2010 , alcanzando los 4,4 puntos porcentuales en las presidenciales de 2012. La volatilidad media agregada - votantes que cambiaron en sentido de su voto en términos absolutos - en el periodo objeto de estudio fue del $18,6 \%$ en la liza legislativa y del $15 \%$ en la presidencial (PELA 2010-2012).

Para verificar si las asignaciones se realizan con el propósito de movilizar o recompensar el apoyo al partido oficialista de turno, se analiza la ejecución presupuestaria de los rubros "seguridad social" y "asistencia social" de la partida de Servicios Sociales ${ }^{2}$ del gobierno central de la República Dominicana en 2006-2012. Desde que en 2005 se implementara el PTC «Solidaridad», se han celebrado dos contiendas legislativas y una presidencial. La cuantía y regularidad del gasto en "seguridad social" y "asistencia social" son indicadores del peso de la redistribución programática y táctica en el país que permiten responder a la pregunta: ¿cuándo domina una sobre otra?

Se sostiene como hipótesis que las oscilaciones en la ejecución del gasto focalizado están determinadas por la cercanía de las elecciones, en una estrategia ex ante de redistribución táctica que prioriza la atención a los grupos vulnerables con fines movilizadores propia de escenarios desideologizados competitivos. La débil profesionalización de la Administración dominicana permite a las agencias encargadas de ejecutar este tipo de asistencia social selectiva utilizar el patronazgo ex post para recompensar y mantener las lealtades.

\section{Panorama de la protección PRE- VISIONAL Y COMPENSATORIA EN AMÉ- RICA LATINA}

Más de la mitad de los latinoamericanos no están cubiertos por sistemas previsionales frente a contingencias como la maternidad, el desempleo, la enfermedad o los accidentes. La mayor cobertura de las clases medias y altas contrasta con la desprotección de las rentas bajas. En 2012, solo el 21,6 \% de los latinoamericanos más vulnerables estaban afiliados a la Seguridad Social, lejos del $78,2 \%$ de los más pudientes (CEPAL 2012).
En el caso de la jubilación, apenas el $6 \%$ de los adultos mayores hondureños tenían derecho a una pensión contributiva, al igual que el $16 \%$ de los dominicanos o el $33 \%$ de los ecuatorianos. Estas cifras contrastan con la vocación universal de sistemas previsionales más consolidados como el chileno o el uruguayo, en los que el $80 \%$ de la población de más de 65 años recibía en 2011 una pensión tras el cese de su vida activa (Abramo 2016: 26). El análisis desagregado por países muestra una fotografía con escenarios de vocación universalista en el Cono Sur, intermedios en Venezuela y Ecuador y otros regresivos en Colombia, El Salvador o Guatemala. En este país, solo el $0,6 \%$ de los guatemaltecos ubicados en el quintil bajo estaban afiliados a la seguridad social, frente al 58,1 $\%$ de los uruguayos en similares condiciones económicas. En el nivel medio de ingresos, el 66,1 \% de los brasileños asalariados cotizaba al sistema, mientras que solo lo hacía el $14,5 \%$ de los paraguayos.

Por el contrario, el porcentaje de receptores de PTC ha aumentado en un $73 \%$ desde la pasada década $^{3}$. En 2012, cerca de 130 millones de latinoamericanos eran beneficiarios de algún PTC, frente a los 29 millones del año 2002. Su amplia cobertura contrasta con su naturaleza poco gravosa, ya que los recursos que destinaron los gobiernos representaron el 0,4\% del PIB regional, oscilando entre el $0,51 \%$ de México y el $0,02 \%$ del PIB de El Salvador (CEPAL 2012: 7). Ecuador lideraba en 2010 el ranking con un 44,3 $\%$ de receptores; en posiciones intermedias se ubicaban Guatemala (22,6 \%) y República Dominicana $(21,2 \%)$, y cerraba la lista Costa Rica con un 3,3\% total de población beneficiaria. A nivel desagregado, la cobertura evidencia la dispar incidencia absoluta de los PTC. En Paraguay, el 13,9 \% de la población pobre recibía la transferencia, al igual que el $46,3 \%$ y el $17,4 \%$ en similares condiciones económicas en Dominicana y Costa Rica, respectivamente; mientras que el $100 \%$ de los indigentes y el $84,6 \%$ de los pobres estaban adscritos, en 2010, al «Bolsa Familia» en Brasil. Con respecto al impacto en el ingreso, el promedio regional de la cuantía mínima de las transferencias cubría el 29,3\% del déficit mensual medio de recursos de la población indigente y el 15,2 \% de la población pobre (Cecchini y Madariaga 2011: 125).

\section{La protección social en la República Domi- nicana}

La República Dominicana es uno de los países con menor gasto social por habitante de América Latina. En 2006 destinó el 6,4 \% del PIB, cinco puntos por debajo de la media regional, que alcanzaba el 11,5\%. En 2012 la inversión social de la región se elevó al 13,6 \%, mientras que la nacional incrementaba en un punto porcentual $(7,3 \%$ del PIB). Estos datos contrastan con el crecimiento del 4,7\% del PIB en el periodo 2004-2012, muy por encima de la media de sus vecinos latinoamericanos - que, a pe- 
Tabla 1.

Asalariados que cotizan o están afiliados a la Seguridad Social (\%), 2012

\begin{tabular}{|l|c|c|c|}
\hline & Quintil bajo & Quintil medio & Quintil alto \\
\hline Chile & 63,2 & 71,2 & 99,8 \\
\hline Uruguay & 58,1 & 79,2 & 94,1 \\
\hline Costa Rica & 51,1 & 65,6 & 85,0 \\
\hline República Dominicana & 37,6 & 51,6 & 91,0 \\
\hline Brasil & 36,9 & 66,1 & 83,3 \\
\hline Venezuela & 32,3 & 52,3 & 83,9 \\
\hline Argentina & 27,8 & 45,9 & 89,2 \\
\hline Panamá & 27,7 & 61,9 & 88,4 \\
\hline Ecuador & 22,4 & 41,7 & 77,3 \\
\hline El Salvador & 6,7 & 20,0 & 67,4 \\
\hline México & 4,7 & 27,6 & 70,2 \\
\hline Nicaragua & 4,7 & 20,0 & 57,9 \\
\hline Bolivia & 4,5 & 11,4 & 83,6 \\
\hline Colombia & 4,0 & 36,6 & 57,3 \\
\hline Paraguay & 3,6 & 14,5 & 60,5 \\
\hline Perú & 1,9 & 17,8 & 66,7 \\
\hline Honduras & 1,0 & 11,7 & 66,2 \\
\hline Guatemala & 0,6 & 10,6 & $\mathbf{7 8 , 2}$ \\
\hline Promedio América Latina & $\mathbf{2 1 , 6}$ & $\mathbf{3 9 , 2}$ & \\
\hline
\end{tabular}

Fuente: BID, open data.

sar de ello, evidenciaron importantes mejoras redistributivas ${ }^{4}$ - y fue el único país de la región donde el salario mínimo real retrocedió durante la pasada década (OIT 2011).

El modelo de industrialización por sustitución de importaciones en la República Dominicana (19681974) no produjo los resultados esperados en la proletarización de la fuerza laboral, ni en la conformación de un interés de clase en la etapa fundacional de su régimen de bienestar (Faxas 2007; Báez 2011). El alto grado de informalidad del mercado laboral dominicano orientó la protección social hacia modelos clientelares de auxilio. El resultado fue un sistema excluyente que protegía el trabajo formal urbano, de cobertura estratificada, y que privilegiaba a altos rangos funcionariales con el que el régimen balaguerista (1966-1978) aseguraba su adhesión.

Como muchos de sus vecinos, que acometieron reformas de retorno estatal durante el giro a la izquierda, el país emprende la construcción del Sistema Dominicano de Seguridad Social (SDSS) en 2001, con la llegada al poder del socialdemócrata Partido Revolucionario Dominicano (PRD). A pesar del tiempo transcurrido, la universalización de su cobertura es uno de sus retos, ya que en 2012 este régimen contributivo de capitalización individual protegía solo al $47,1 \%$ de la población ${ }^{5}$. En ese año, el $37,6 \%$ de los trabajadores del quintil bajo estaban afiliados al SDSS y el $85 \%$ de los asalariados del quintil alto (BID 2012); una protección de la que que- dan excluidos el $49 \%$ de los empleados en la economía informal. Los ingresos tributarios para financiar el sistema disminuyeron del $14 \%$ de 2006 al 12,3 $\%$ del PIB en 2010. La presión fiscal dominicana es una de las más bajas de América Latina, cuya media regional alcanzaba en 2012 el $21,5 \%$ del PIB.

La atención a los sectores vulnerables a través de la asistencia focalizada se inicia en 2004 con el cambio de administración, bajo la presidencia de Leonel Fernández del Partido de la Liberación Dominicana (PLD), y se ha consolidado con los gobiernos del también oficialista Danilo Medina (2012-2016 y 2016-2020). La Administración de Subsidios Sociales (ADESS) gestiona actualmente siete subsidios de los que se benefician cerca de 900.000 familias. En 2012, estas asignaciones se unieron a la ejecutada por la Oficina de la Primera Dama - y vicepresidenta bajo el gobierno de Danilo Medina - Margarita Cedeño, pasando a denominarse «Progresando con Solidaridad». Las unidades de intervención de este PTC son familias en situación de pobreza extrema y moderada identificadas por el Sistema Único de Beneficiarios (SIUBEN), según su ubicación en el Índice de Calidad de Vida (ICV), y tiene como objetivo asegurar a las familias un nivel de consumo básico ${ }^{6}$. Su cuantía no depende del IPC y su recepción no está vinculada a servicios de inserción laboral, acompañamiento familiar o mejoramiento de la vivienda. A pesar de su amplia cobertura, el BID ha alertado del descenso de la progresividad de las transferencias, su baja incidencia absoluta y la elevada tasa de filtración. En 2010, el 46,8 \% de los receptores no 
calificaba como pobre, mientras que el 52,5\% de los indigentes dominicanos no recibía asignación monetaria alguna (Carrasco et al. 2016: 31).

Este ejercicio de incorporación social segmentada del gobierno dominicano se complementa con una red inconexa de programas asistenciales y agencias públicas, como los populares «Comunidad Digna», los «Comedores Económicos» o el Despacho de la Primera Dama, entre otros ${ }^{7}$. También los legisladores dominicanos ejercen de gestores de pensiones selectivas y ayudas sociales en sus distritos, a través del «Fondo de Gestión Social Legislativa», haciendo uso de su potestad discrecional de incluir beneficiarios especiales al margen de los protocolos contributivos ${ }^{8}$. En el periodo 1998-2010, el 34 \% de las proposiciones de ley de los diputados dominicanos tuvo como objetivo gestionar la concesión de una pensión para un elector de su circunscripción. En el año 2006, este tipo de iniciativas representaron el $67,8 \%$ del total de la actividad propositiva y, en 2010, el 25,7 \% (Benito 2017: 160). Este desplazamiento del Legislativo en las actividades de reparto de prebendas sociales podría estar condicionado por el mayor protagonismo alcanzado por el Ejecutivo con los PTC.

\section{COMPETICIÓN ELECTORAL Y GASTO SO- CIAL EN LA REPÚBLICA DOMINICANA}

Durante tres décadas (1966-1998), la política dominicana estuvo regida por la competencia carismática alrededor del cleavage autoritarismo-democracia entre los caudillos Joaquín Balaguer del Reformista Social Cristiano (PRSC), Juan Bosch del PLD y Francisco Peña Gómez del PRD. Tras su desaparición, los partidos dominicanos se han adaptado al escenario de la democratización conservando el viejo estilo de la política de clientela y manejo patrimonial del Estado, en una competencia "atrapalotodo" en el espectro del centro derecha ${ }^{9}$. Como han demostrado algunos trabajos, aunque la escala izquierdaderecha funciona como atajo informativo en el país, esta carece de contenido programático (Carlin, Singer y Zechmeister 2015) y de incidencia alguna en la decisión de voto de los dominicanos (Rico y Torcal 2018: 122). Su función movilizadora no programática gira en torno a su efectividad para distribuir bienes y la alternancia está marcada por el ritmo del desempeño macroeconómico (Singer y Carlin 2013; Benito 2018). Por el contrario, la identificación partidaria vínculo afectivo entre político y elector- es alta y estable, mayor entre los votantes menos educados

Tabla 2.

Transferencias condicionadas Programa Solidaridad 2005-2012

\begin{tabular}{|c|c|c|c|c|c|c|c|c|}
\hline Transferencia & $\begin{array}{l}\text { Criterio de } \\
\text { elegibilidad }\end{array}$ & Receptor & Forma de pago & Periodicidad & $\begin{array}{l}\text { Máximo por } \\
\text { familia }\end{array}$ & Condicionalidad & Sanciones & $\begin{array}{c}\text { min.-máx. } \\
\text { hogar }\end{array}$ \\
\hline $\begin{array}{l}\text { «Comer es } \\
\text { primero» }\end{array}$ & $\begin{array}{l}\text { Hijos e hijas } \\
\text { hasta } 14 \text { años. } \\
\text { Mujeres emba- } \\
\text { razadas. } \\
\text { Jefas y jefes } \\
\text { de hogar. } \\
\text { Adultos mayo- } \\
\text { res sin trabajo. }\end{array}$ & $\begin{array}{l}\text { Jefa o jefe } \\
\text { de hogar }\end{array}$ & \multirow{5}{*}{$\begin{array}{l}\text { Tarjeta magné- } \\
\text { tica, transferen- } \\
\text { cia plana, uso } \\
\text { intermedio. }\end{array}$} & Mensual & $\begin{array}{l}\text { Una transfe- } \\
\text { rencia }\end{array}$ & \multirow{3}{*}{$\begin{array}{l}\text { Educación: } \\
\text { Asistencia escolar } \\
\text { mínima del } 80 \% \text { y } \\
\text { aprobación del curso. } \\
\text { Salud: Asistencia a } \\
\text { controles de salud } \\
\text { para menores de } 5 \\
\text { años. Asistencia a } \\
\text { capacitaciones. } \\
\text { Identificación: trami- } \\
\text { tación y obtención de } \\
\text { documentos de iden- } \\
\text { tidad de miembros } \\
\text { de la familia (acta de } \\
\text { nacimiento o cédula } \\
\text { de identidad). }\end{array}$} & $\begin{array}{l}\text { Suspensión por } \\
\text { incumplimiento } \\
\text { en tres perio- } \\
\text { dos consecu- } \\
\text { tivos. }\end{array}$ & 5-5 USD \\
\hline $\begin{array}{l}\text { «Incentivo a } \\
\text { la asistencia } \\
\text { escolar» }\end{array}$ & $\begin{array}{l}\text { Hijos e hijas } \\
\text { entre } 4 \text { y } 21 \\
\text { años matri- } \\
\text { culados en } \\
\text { la educación } \\
\text { pública. }\end{array}$ & $\begin{array}{l}\text { Jefa a jefe } \\
\text { de hogar }\end{array}$ & & Bimestral & $\begin{array}{l}\text { Cuatro be- } \\
\text { neficiarios }\end{array}$ & & $\begin{array}{l}\text { Suspensión } \\
\text { definitiva por } \\
\text { condicionalidad } \\
\text { en tres perio- } \\
\text { dos consecu- } \\
\text { tivos. }\end{array}$ & 2-4 USD \\
\hline $\begin{array}{l}\text { «Apoyo } \\
\text { adultos } \\
\text { mayores» }\end{array}$ & $\begin{array}{l}\text { Mayores de } 65 \\
\text { años desem- } \\
\text { pleados que } \\
\text { no reciben otra } \\
\text { pensión. }\end{array}$ & $\begin{array}{l}\text { Destinata- } \\
\text { rio directo }\end{array}$ & & Bimestral & No tiene & & No & 3-3 USD \\
\hline «Bono Gas» & $\begin{array}{l}\text { Hogares po- } \\
\text { bres y de clase } \\
\text { media baja }\end{array}$ & Hogar & & Mensual & $\begin{array}{l}\text { Una transfe- } \\
\text { rencia }\end{array}$ & No & No & 2-2 USD \\
\hline «Bono Luz» & $\begin{array}{l}\text { Hogares de es- } \\
\text { casos recursos } \\
\text { que reciben } \\
\text { Bono Gas. }\end{array}$ & Hogar & & Mensual & $\begin{array}{l}\text { Una transfe- } \\
\text { rencia }\end{array}$ & No & No & 7-14 USD \\
\hline
\end{tabular}

Fuente: Elaboración propia con datos de Cecchini y Madariaga (2011). 
Tabla 3

Razones de la elección de los diputados en la República Dominicana (\%)

\begin{tabular}{|c|c|c|c|c|c|c|c|c|c|}
\hline & \multicolumn{3}{|c|}{ Legislatura 2002} & \multicolumn{3}{|c|}{ Legislatura 2006} & \multicolumn{2}{|c|}{ Legislatura 2010} & \multirow{2}{*}{ Promedio } \\
\hline & PLD & PRD & PRSC & PLD & PRD & PRSC & PLD & PRD & \\
\hline Simpatía & 29,0 & 38,6 & 41,4 & 57,4 & 65,4 & 60 & 18,4 & 37,7 & 43,4 \\
\hline Campaña electoral & 16,1 & 35,1 & 34,5 & 25,9 & 15,4 & 10 & 26,3 & 16,1 & 22,4 \\
\hline Apoyo del líder del partido & 25,8 & 5,3 & 10,3 & 1,9 & 0 & 10 & 10,5 & 5,8 & 8,7 \\
\hline Experiencia anterior & 12,9 & 7 & 0 & 1,9 & 7,7 & 10 & 15,8 & 10,8 & 8,2 \\
\hline Programa & 9,7 & 7 & 10,3 & 1,9 & 3,8 & 0 & 7,9 & 5,4 & 5,7 \\
\hline Ideología & 3,9 & 3,5 & 0 & 7,4 & 7,7 & 0 & 0 & 5,4 & 3,4 \\
\hline Tradición familiar & 0 & 3,5 & 3,4 & 1,9 & 0 & 10 & 0 & 2,7 & 2,6 \\
\hline Otras & 2,6 & 0 & 0,1 & 1,7 & 0 & 0 & -- & -- & -- \\
\hline Experiencia del diputado & -- & -- & -- & -- & -- & -- & 21,1 & 16,1 & -- \\
\hline
\end{tabular}

Fuente: PELA, Universidad de Salamanca.

y asienta sus raíces en el personalismo y el contacto directo con partidos y candidatos (Torcal, Maldonado y Rodríguez 2018: 213). Las percepciones de los legisladores dominicanos sobre las razones que fundamentaron su elección muestran que la simpatía ha sido la motivación principal del voto, así como el exiguo peso del programa en la competición interpartidista en el periodo objeto de estudio:

Este escenario de escasa vinculación ideológicoprogramática se asemeja al identificado por Dixit y Londregan (1996) como propicio para la redistribución táctica y la atracción de votantes dispuestos a cambiar la orientación de su voto. Para conseguir la reelección, los diputados entrevistados consideraron que "atender a los electores del distrito" (36,5 \%) y "tener presencia permanente" $(33,2 \%)$ resultaban claves para el éxito electoral, frente a tener un programa $(2,8 \%)$ o el apoyo del líder del partido (0 \%) (PELA 2010-2012). Esta independencia en el estilo de la representación y la naturaleza personalista del voto - alentada por un sistema de listas abiertas y circunscripciones pequeñas (Allen 2015; Jacobs y Spierings 2010) - revelan la interacción en el país de los llamados "servidores del distrito" y "empresarios políticos" (Siavelis y Morgenstern, 2008: 105). En esa búsqueda de votos personales, el efecto movilizador del clientelismo se activa durante la campaña y se gestan las expectativas de reciprocidad. En 2010, la República Dominicana ocupaba el primer lugar en la escala de clientelismo, según El Barómetro de Las Américas (LAPOP 2010), en reparto de prebendas en campaña electoral por parte de los legisladores (PELA 2010-2012) y se situaba en la comparación mundial entre los tres países más clientelares, junto a Senegal y Mongolia (Kitschelt y Kselman 2011: 33). La República Dominicana lidera la comparativa regional en reparto de prebendas, empleos y atención a los intereses parroquiales del distrito como incentivo para obtener votos. El $68 \%$ de los diputados dominicanos entrevistados dijo prometer con mucha frecuencia acceso al empleo público, frente al 14,4 $\%$ de los legisladores uruguayos (PELA 2010-2012).

Las ayudas asistenciales también forman parte de la oferta de campaña en esta competencia por la efectividad en la distribución de bienes selectivos. En las legislativas y municipales de 2010, la oposición denunció el uso de los recursos públicos que hacian los candidatos oficialistas en el programa «Comedores Económicos Móviles del Estado» o el reparto de electrodomésticos de la Administración de Lotería a los beneficiarios del PTC «Solidaridad $»^{10}$. Ante tales denuncias, la Junta Central Electoral (JCE) decretó la suspensión de los planes sociales del gobierno como medida cautelar desde el día 14 al 17 de mayo ${ }^{11}$, circunstancia que fue aprovechada por el partido oficialista, que lanzó a los medios el eslogan radiofónico: "EI PRD no quiere que la gente pobre coma". A esta prohibición se sumó la recomendación de la JCE de retener la ejecución del «Fondo de Gestión Social Legislativa», por ser un medio inapropiado de financiamiento de las actividades proselitistas de los legisladores que aspiraban a su reelección. Este uso de recursos públicos en la campaña —que incluye desde el reparto de raciones de comida a la asignación selectiva de pensiones por la vía del decreto presidencial- fue una de las observaciones del Informe Final de la misión electoral de la Organización de Estados Americanos (OEA) en la contienda de 2012.

Las 900.618 familias beneficiarias de la «Tarjeta Solidaridad» representaban el $9 \%$ de la población y el $14 \%$ del censo electoral en 2012. Según el Barómetro de Las Américas, en ese mismo año el 31,3 $\%$ de los entrevistados dijo tener la tarjeta y el país ocupaba el segundo puesto en receptores de este tipo de asistencia pública $(22,6 \%)$, por debajo de Bolivia $(54,9 \%)$, que ocupaba el primer lugar y lejos de Honduras (4,9\%), en el último puesto (LAPOP 2012: 31). El análisis de regresión realizado por los autores revelaba que las personas con mayor probabilidad de ser beneficiarias eran las que simpatizaban con 
Tabla 4

Candidatos/partidos que prometen o entregan incentivos para obtener votos (\%)

\begin{tabular}{|l|c|c|c|c|}
\hline & Bienes de consumo & $\begin{array}{c}\text { Beneficios para su comunidad } \\
\text { o distrito }\end{array}$ & $\begin{array}{c}\text { Acceso preferencial a un } \\
\text { trabajo en el sector público }\end{array}$ & Promedio \\
\hline República Dominicana & 85,7 & 70,9 & 68,4 & $\mathbf{7 5 , 0}$ \\
\hline Honduras & 87,8 & 61 & 64,6 & $\mathbf{7 1 , 1}$ \\
\hline Guatemala & 66,4 & 70,3 & 58 & $\mathbf{6 4 , 9}$ \\
\hline Perú & 66,9 & 62,8 & 52,6 & $\mathbf{6 0 , 8}$ \\
\hline Costa Rica & 48,2 & 71,4 & 44,6 & $\mathbf{5 4 , 7}$ \\
\hline Brasil & 51,4 & 69,4 & 37,8 & $\mathbf{5 2 , 9}$ \\
\hline Ecuador & 54,1 & 51,9 & 35,9 & $\mathbf{4 7 , 3}$ \\
\hline Argentina & 46,5 & 52,1 & 40,3 & $\mathbf{4 6 , 3}$ \\
\hline El Salvador & 50,1 & 50,1 & 37,1 & $\mathbf{4 5 , 8}$ \\
\hline Colombia & 37,5 & 48,4 & 43,1 & $\mathbf{4 3 , 0}$ \\
\hline Bolivia & 35,2 & 45,2 & 24,5 & $\mathbf{3 5 , 0}$ \\
\hline Uruguay & 10,2 & 23,8 & 14,4 & $\mathbf{1 6 , 1}$ \\
\hline Chile & 15,1 & 22,1 & 4,7 & $\mathbf{1 4 , 0}$ \\
\hline
\end{tabular}

Fuente: PELA, Universidad de Salamanca. CLIEN1: “¿Podría decirme si se utilizan en su país con mucha frecuencia los siguientes incentivos para obtener votos?". Fecha encuesta: RD (2011); HND (2010); GTM (2012); PER (2011); CR (2010); BR (2010); EC (2009); ARG (2010); SLV (2009); COL (2011); BOL (2010); URG (2010); CHL(2010).

el oficialista PLD, las de menor riqueza y nivel educativo y de menos edad (Espinal, Morgan y Seligson 2013: 33). Estos resultados confirmarían la preferencia de asignación a los grupos con menor nivel de renta y mayor utilidad marginal del ingreso en el modelo estratégico swing voter de Dixit y Londregan (1996). Una de las condicionalidades de este PTC es haber iniciado la tramitación para la obtención de la cédula de identidad necesaria para ejercer el derecho al sufragio. Teniendo en cuenta que el 3,9\% de la población dominicana carecía de registro civil (ONE 2011), el programa es un incentivo para incrementar la participación de sectores hasta entonces excluidos del derecho al sufragio.

Con respecto a la supervisión de la lealtad en el intercambio clientelar, en la República Dominicana el monitoreo se apoya en una red informal de activistas que se sitúan en las puertas de los centros de votación. Puesto que el censo incluye la foto de los electores, los activistas pueden cotejar quién vota. Como reconocía uno de ellos: "nuestra misión es ir viendo quién viene a votar $y$, si a las tres de la tarde no se han presentado, entonces vamos a buscarlos a casa" (Benito 2011: 400). En las elecciones de 2012, la JCE prohibió el uso de teléfonos móviles en los colegios electorales dominicanos para evitar que los partidos recompensaran a aquellos que enseñaran la foto que confirmara su elección en las urnas. Este tipo de movilización para premiar a los leales y persuadir a los indecisos es utilizada por todos los partidos dominicanos. Sirva como ejemplo la campaña presidencial de 2012, cuando, ante el temor de que un cambio de gobierno diese fin a la «Tarjeta Solidaridad», el candidato por el PRD anunciaba: "Si vuelvo al Palacio lo único que haré será cambiar el color a las tarjetas (...) Si llego al poder habrá una rosadita para los compatriotas, la verdecita para ustedes [los seguidores del partido MODA, aliado] y la morena para el PRD"12.

\section{Los datos}

Para verificar si las asignaciones se realizan con el propósito de movilizar o recompensar el apoyo al partido oficialista de turno, se analiza la ejecución de los rubros presupuestarios "seguridad social" y "asistencia social" como indicadores de la redistribución programática y táctica, respectivamente, en 2006-2012, periodo en el que tienen lugar dos contiendas legislativas y una presidencial. La partida "asistencia social" incluye los PTC del Gabinete Social de la Vicepresidencia y otros programas de subsidios y prebendas, como el de la Primera Dama. Los datos agregados del gráfico 2 revelan la preferencia de gasto en asistencia social en año electoral. Aunque esta partida se mantuvo prácticamente estable y la que sufraga la seguridad social experimenta alzas y bajas en torno al $30 \%$-en principio contrarias a la naturaleza estable de la redistribución programática-, el análisis desagregado muestra, por el contrario, una ejecución mensual discontinua y estratégica tras la aparente estabilidad cíclica de la asistencia social.

Como revelan los gráficos 2 y 3 , la ejecución presupuestaria en 2006 y 2010 en que se celebran elecciones legislativas sigue un patrón similar: la partida de los programas de asistencia supera a la dedicada a financiar la seguridad social nacional. La estabilidad del gasto en esta última contrasta con los vaivenes de la asistencia focalizada, que experimenta picos máximos de gasto un mes antes de la cita con las urnas e incluso durante el mismo mes de mayo en que se celebran las contiendas electorales en la República Dominicana. Este patrón de comportamiento podría obedecer a una estrategia movilizadora contingente y autónoma para persuadir a votantes opositores y/o indecisos en la forma identificada por Stokes (2005). 


\section{Gráfico 1}

Gasto en seguridad social y asistencia social (media anual)

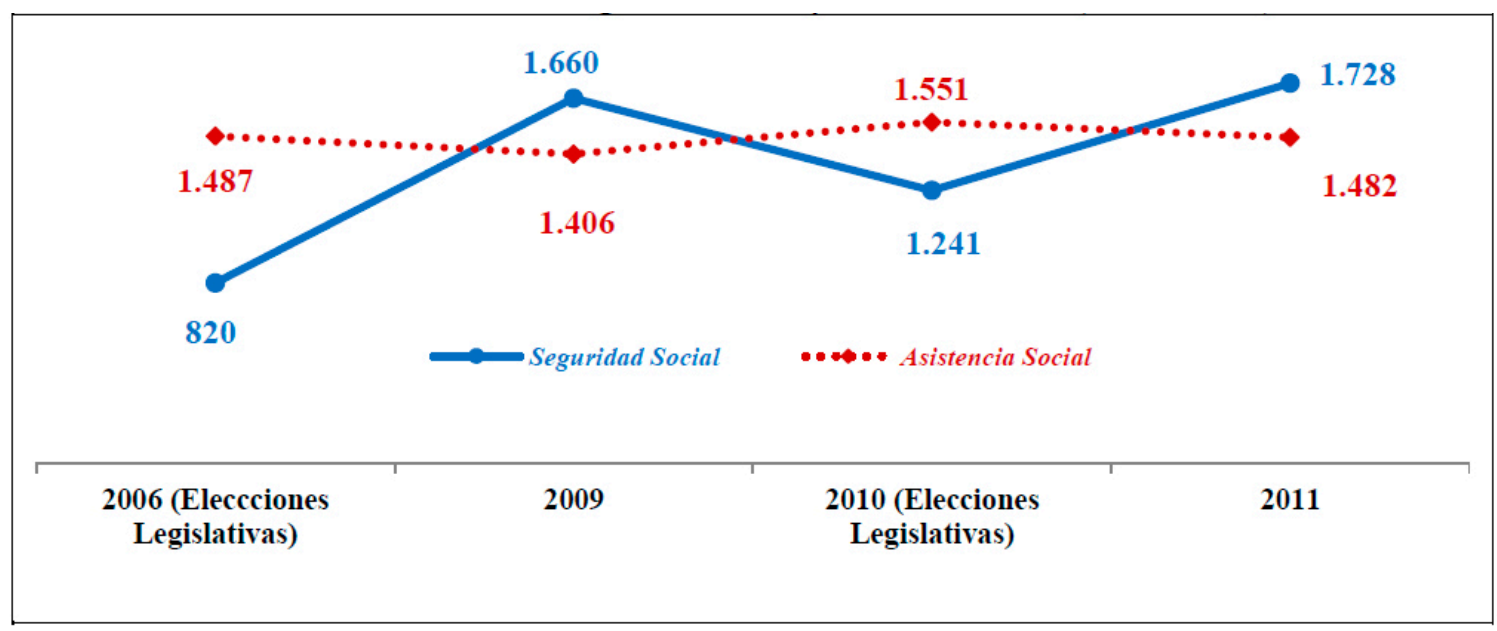

Fuente: DIGEPRES. Cifras en millones de pesos dominicanos (DOP).

\section{Gráfico 2}

Gasto en seguridad social y asistencia social, año electoral 2006

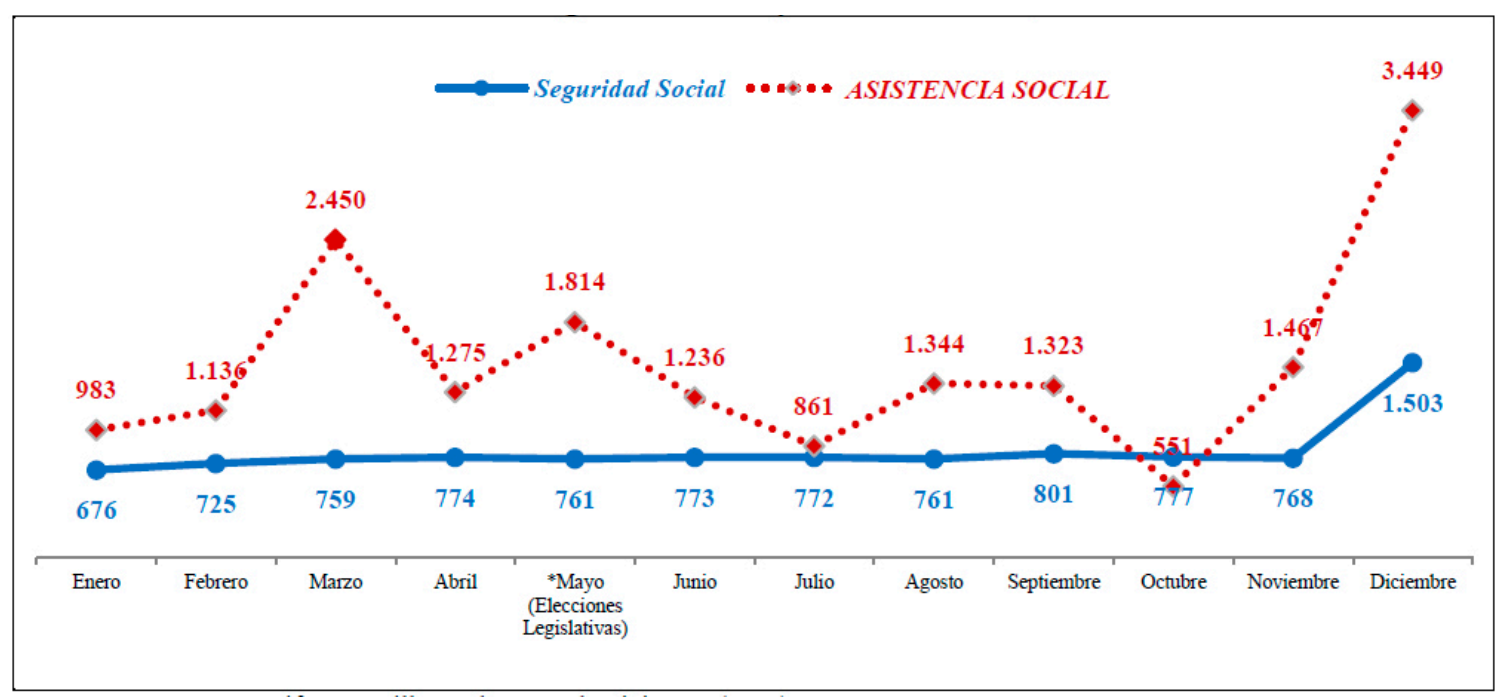

Fuente: DIGEPRES. Cifras en millones de pesos dominicanos (DOP).

\section{Gráfico 3}

Gasto en seguridad social y asistencia social, año electoral 2010

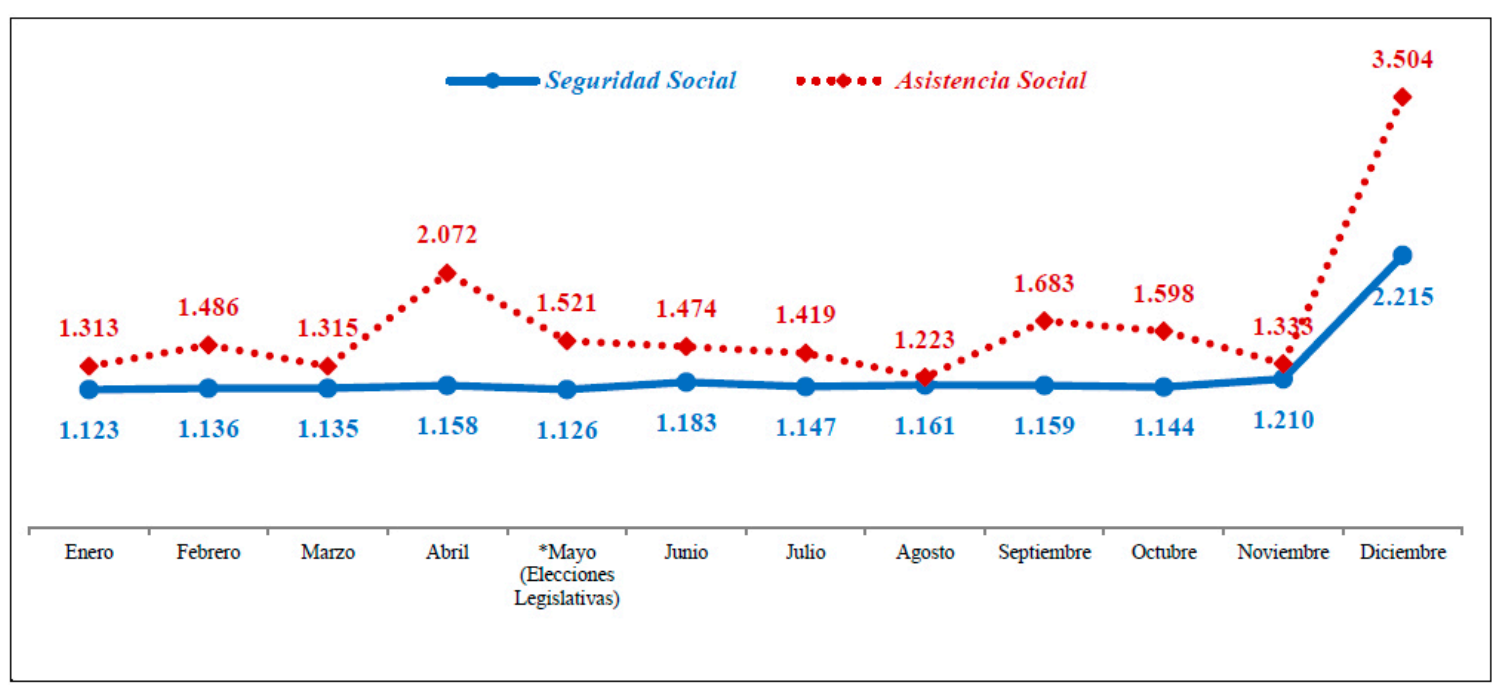

Fuente: DIGEPRES. Cifras en millones de pesos dominicanos (DOP). 
El dispendio en programas asistenciales se recupera en agosto -aunque sin alcanzar el nivel de gasto movilizador ex ante-cuando toman posesión los representantes elegidos y se inicia la nueva Legislatura.

Estas asignaciones de menor cuantía ex post podrían tener el propósito de premiar a los votantes fieles una vez constatada la lealtad, en un patrón similar al advertido por Ansolabehere y Snyder (2003) y Nitcher (2008). En 2006, dos meses antes de las elecciones, el gasto medio mensual en asistencia social fue de un $77 \%$ superior al de octubre de ese mismo año. De igual manera, la partida ejecutada en agosto de 2010 fue un 40 \% menor a la de abril previo a la cita con las urnas. La resolución de la JCE del 11 de mayo de 2010 — seis días antes de las elecciones-, decretando la suspensión temporal de los planes sociales del gobierno ante las denuncias de la oposición, podría explicar la diferencia de menor gasto en esa misma fecha en la anterior cita electoral del año 2006, en la que el PLD conquistaba por primera vez en su historia la mayoría en el Legislativo.
En los años en que no se celebran elecciones (gráficos 4 y 5) se invierte la tendencia y la línea de gasto en seguridad social supera a la partida que sufraga la asistencia social, si bien en esta se observan picos en marzo, mayo y septiembre que se corresponden con el tradicional dispendio con ocasión de la Semana Santa, el Día de las Madres y la vuelta al colegio, respectivamente ${ }^{13}$. En los cuatro años considerados y en ambas partidas, el presupuesto se dispara en el último mes del año. Diciembre es la época por excelencia para el reparto de prebendas, siguiendo la tradición inaugurada por Joaquín Balaguer, en la que los funcionarios nacionales, provinciales y municipales entregan canastas navideñas, alimentos y regalos. Estas entregas puntuales de bienes evidencian que, si bien la cercanía de la cita con las urnas activa la maquinaria clientelar, los intercambios particularizados y la relación patrón-cliente continúan durante el mandato de representación. En el caso de la partida de seguridad social, el coste aumenta con el salario número 13 y el bono de Navidad de los empleados.

\section{Gráfico 4}

Gasto en seguridad social y asistencia social, año NO electoral 2009

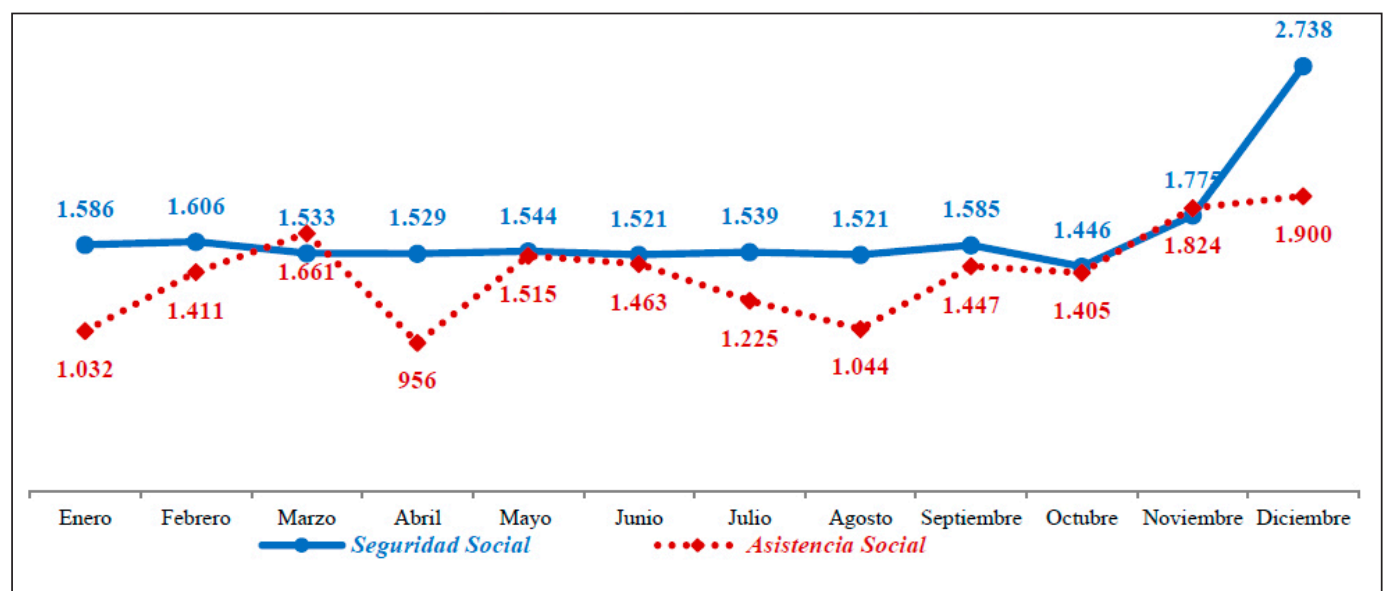

Fuente: DIGEPRES. Cifras en millones de pesos dominicanos (DOP).

Gráfico 5

Gasto en seguridad social y asistencia social, año NO electoral 2011

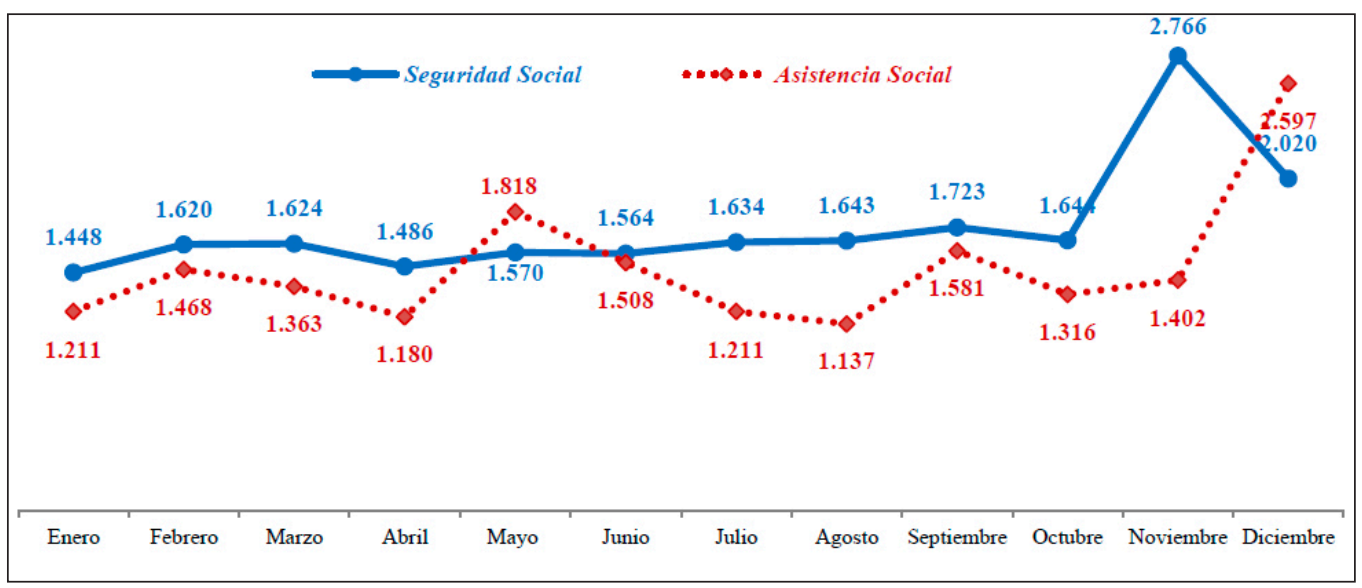

Fuente: DIGEPRES. Cifras en millones de pesos dominicanos (DOP). 
Una mirada al número de empleados contratados para la gestión de transferencias monetarias da cuenta del sometimiento de la Administración dominicana a los ciclos electorales, en ausencia de la profesionalización de la carrera civil. A pesar de los esfuerzos de las últimas décadas, la discrecionalidad y los vínculos de lealtad personal y política caracterizan la selección y gestión burocrática de muchas de las democracias latinoamericanas (Ferraro 2009). La primera Ley de Servicio Civil en la República Dominicana se promulgó en 1991. Desde entonces, han sido lentos los avances en el establecimiento de la carrera civil, que recibía un impulso en 2008 con la creación del Ministerio de Administración Pública y la Ley N. ${ }^{\circ}$ 41 de Función Pública. En 2012, solo el $10 \%$ de los servidores de la Administración central había ingresado en la carrera pública y eran inamovibles (MAP 2012). En el periodo 2004-2012, apenas 217 de los 479.400 funcionarios dominicanos accedieron por la vía del concurso, representando el 0,04\% del total (Suárez 2013: 24).

En este escenario, el control de los empleos públicos permite al partido oficialista utilizar el patronazgo para premiar lealtades políticas. Generalmente, estos puestos suelen estar ocupados por hombres del partido, al que deben su puesto en la Administración, y trabajan de "bróker" para el partido controlando las redes de patronazgo en las instituciones públicas. Este "profesional camuflado" (Panebianco 1982) es un perfil habitual en la organización informal de los partidos-máquina dominicanos y confirmaría la tesis de Kramon y Posner (2013) de que el tipo de estrategia de distribución depende del bien selectivo entregado.

Como revela el gráfico 6, la estabilidad en el número de empleados del PTC «Solidaridad» en el año no electoral 2011, contrasta con el incremento de hasta un $56 \%$ tras las legislativas de 2010 y de un $23 \%$ más en el número de contrataciones después de las presidenciales de 2012. Puesto que los picos máximos de contratación corresponden al mes de agosto - cuando comienza el nuevo mandato de los legisladores y del presidente electo-, estos podrían tener una naturaleza de recompensa ex post por el apoyo prestado al partido. En agosto del 2010, año electoral, el programa llegó a contar con 3.012 empleados a su servicio y un año después operaba con solo 1.686 .

La contratación de empleados para la ejecución de los programas asistenciales del Despacho de la Primera Dama evidencia el sometimiento de la Administración a la carrera política de sus gestores y el uso de su poder de decisión y manipulación como agentes (Dowding 1994). En el periodo 20082012, esta institución administraba subsidios con un presupuesto tres veces mayor al que ejecutaba el Ministerio de la Mujer para el mismo ejercicio (DIGEPRES 2017). En 2011, año no electoral, el número de empleados se mantiene constante con ligeros aumentos, frente a los picos en la contratación observados en 2012, cuando la directora de la institución era también candidata vicepresidencial en las elecciones de ese año. El pico máximo corresponde al mes de marzo, dos meses antes de la cita con las urnas, en que el número de empleados aumenta un $28 \%$. Este incremento en el personal de la agencia pública podría responder al aumento de las actividades asistenciales coincidente con los intereses proselitistas de la propia candidata y gestora. En agosto de 2012, la ex Primera Dama pasa a ser vicepresidenta de la República Dominicana, y el número de funcionarios de la institución se reduce un $87 \%$.

Gráfico 6

Número de empleados del PTC «Solidaridad», 2010-2012

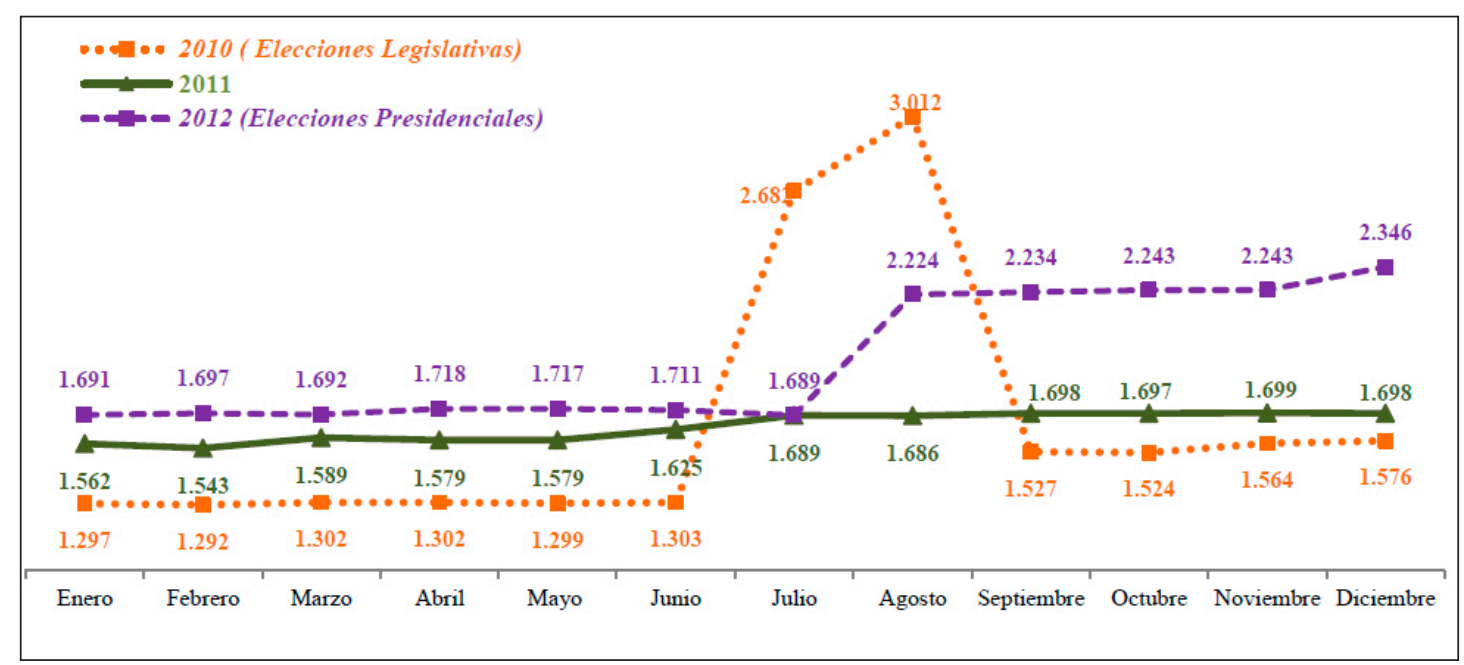

Fuente: SASP (Sistema de Administración de Servicios Públicos). Ministerio de Administración Pública, República Dominicana. 
Gráfico 7

Número de empleados del Despacho de la Primera Dama, 2011-2012

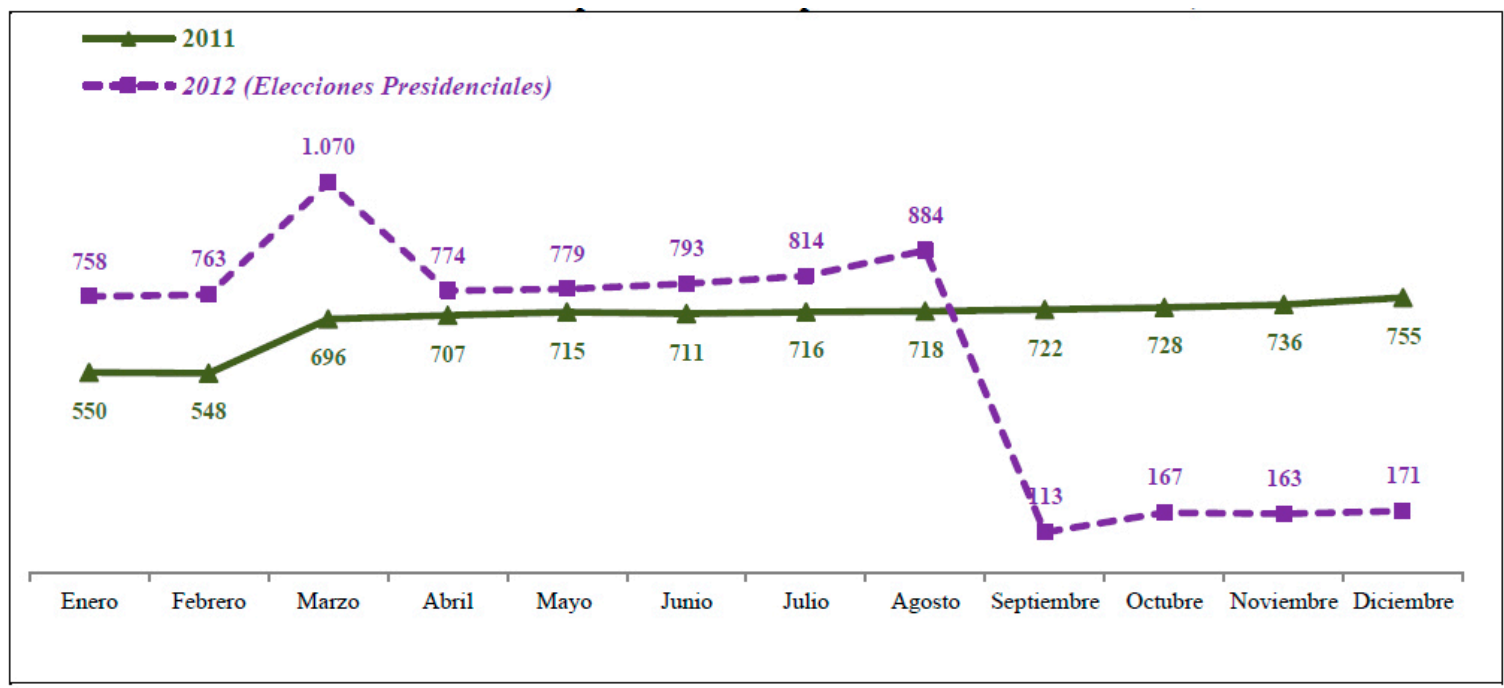

Fuente: SASP (Sistema de Administración de Servicios Públicos). Ministerio de Administración Pública, República Dominicana.

Los datos presentados evidencian que el Ejecutivo prioriza los programas focalizados destinados a satisfacer las necesidades básicas de los sectores pobres en año electoral, en detrimento del gasto en seguridad social. Los vaivenes mensuales en su ejecución no parecen estar relacionados con cambios en el número de beneficiarios potenciales, sino con un patrón contingente de redistribución táctica, ya que la población en condiciones de pobreza extrema y moderada destinataria de los PTC se ha mantenido constante a lo largo de la última década. En 2011, el 32,9\% de los dominicanos se encontraba en situación de pobreza y el 9,05 \% en la indigencia, porcentajes similares a los registrados en el año 2000 (PNUD 2013). El aumento en términos absolutos del gasto en seguridad social podría corresponder con el aumento de la población activa en el periodo estudiado y su incorporación al régimen de protección contributiva $^{14}$. El cambiante número de empleados de las agencias gubernamentales encargadas de gestionar los programas focalizados aporta pistas sobre el incremento interesado de sus actividades con fines movilizadores e instrumentales de recompensa. Esta estrategia distributiva de asignación de bienes que satisfacen necesidades básicas podría haber influido en la consolidación del oficialista PLD como partido predominante en el sistema de partidos dominicano. Estos resultados confirmarían el potencial politizador de la asistencia focalizada que autores como Hevia (2010), Takahashi (2007) o Rocha (2001) han identificado en democracias vecinas, como la mexicana.

\section{Conclusiones}

En el año 2001 la República Dominicana se sumaba a la fase de reformas transformadoras que experimentaron los regímenes de bienestar latinoamericanos en la pasada década, con la creación de la Seguridad Social y la implementación de subsidios condicionados en 2005. Puesto que la mitad de los dominicanos no tiene acceso al régimen previsional contributivo de capitalización individual, depende de los subsidios compensatorios para interrumpir el ciclo de la pobreza. Para atender a estos sectores de la población, desde el año 2004 los gobiernos del PLD han optado por una estrategia de clase distributiva y compensatoria, con gran protagonismo de las transferencias monetarias para conquistar y mantener su base de apoyo social, aunque —como revelan las tasas de pobreza y desigualdad-con escaso poder redistributivo.

Los datos presentados en este trabajo muestran que la dinámica electoral afecta a las decisiones de gasto de la política social en la República Dominicana, a través de una estrategia diversificada que combina políticas particularistas —dirigidas a los sectores económicamente más vulnerables beneficiarios de los programas compensatorios- y políticas programáticas previsionales de carácter contributivo. La débil vinculación ideológica entre ciudadanos y políticos en República Dominicana es el escenario de oportunidad de una redistribución táctica ex ante de transferencias que aseguran un consumo básico, que podría tener por objeto atraer a moderados e indecisos los meses previos a la cita con las urnas. Comida y cheques para movilizar y empleo público para recompensar a los votantes duros que forman parte de la maquinaria del partido, a quienes se recompensa ex post. Esta instrumentalización de las asignaciones monetarias y las ayudas sociales menoscaba los principios de previsibilidad, estabilidad y eficacia que han de guiar laplanificación e implementación de las políticas públicas. El patronazgo en la Administración dominicana podría afectar a la 
imparcialidad de la gestión pública, ya que el interés general puede verse condicionado por los intereses proselitistas del partido oficialista de turno.

El resultado de esta estrategia combinada es un régimen dual de protección social con gran disparidad en la suficiencia y regularidad de las prestaciones que desvirtúa los principios de ciudadanía, solidaridad y equidad. Esta bifurcación entre las políticas del bienestar de excepción —que aseguran un mínimo de subsistencia- y las de seguridad e inserción —que protegen frente a los riesgos comunes de la vidapodría generar una brecha entre dominicanos de primera y segunda clase que dificulte la cohesión social en el país. Esta dinámica no convergente de los mecanismos previsionales y compensatorios de protección social, confirmaría en el país la deriva neoliberal hacia la capitalización individual de los esfuerzos del bienestar latinoamericanos y el auge de la micro financiación de los pobres para asegurar un consumo básico, en el que el objetivo universalista ha dejado de ser el de "ciudadanos iguales" para convertirse en "consumidores iguales" (Lavinas 2013: 13).

\section{NOTAS}

[1] El $10 \%$ de los dominicanos pasó de ser pobre a ser indigente entre 2003 y 2004 (CEPAL 2006-2017). .

[2] La partida de Servicios Sociales se desagrega en ocho rubros: educación, salud, vivienda, agua potable, servicios municipales, recreación y cultura, seguridad social y asistencia social. En el caso del rubro "asistencia social" incluye los PTC del Gabinete Social de la Vicepresidencia y otros programas asistenciales, como el de la Primera Dama.

[3] Argentina (Jefe/as Hogar Desocupados); Bolivia (Bono Juana Azurduny); Brasil (Bolsa Familia); Chile (Chile Solidario); Colombia (Asistencia Escolar); Costa Rica (Avancemos); Ecuador (Bono Desarrollo Humano); El Salvador (Comunidades Solidarias Rurales); Guatemala (Mi Familia Progresa); Honduras (Bono Educación, Salud y Nutrición); México (Oportunidades); Nicaragua (Atención a Crisis); Panamá (Red de Oportunidades); Paraguay (Abrazo); Perú (Juntos); República Dominicana (Prosoli); Uruguay (Asignaciones Familiares).

[4] En 2002-2013, todos los países latinoamericanos redujeron la desigualdad salvo Costa Rica y República Dominicana, donde el índice de Gini creció.

[5] El seguro de salud cubría solo al $25 \%$ de la población (ADESS 2012).

[6] Índice construido con el método Proxy Means Testing. Ponderación de 17 variables relacionadas con el tipo de vivienda (material del techo, suelo, acceso a servicios básicos...) y miembros de la familia (jefatura del hogar, educación, ocupación, documentos de identidad...).

[7] Partida denominada "Beneficiarios de programas asistenciales". Ver asignación de ayudas en las webs ministeriales y de los programas en http://www.comunidad-digna. gov.do/ y http://www.comedoreseconomicos.gob.do/.
Este trabajo contribuye a identificar, a la luz del caso dominicano, la variedad de estrategias de manipulación y favoritismo en la distribución del gasto público en las democracias emergentes. El peso del calendario electoral en la regularidad y cuantía de las asignaciones selectivas evidencia que, si bien pueden ser mecanismos eficaces para la consecución de los objetivos de desarrollo humano, también son herramientas atractivas para los buscadores de rentas.

\section{Agradecimientos}

Investigación realizada en el marco del Proyecto $\mathrm{I}+\mathrm{D}+\mathrm{i}$ Competición ideológica y sistema político: escenarios de estabilidad y cambio [Leticia M. Ruiz Rodríguez (dir.), Universidad Complutense de Madrid, Ref.: CSO2015-63555-R] financiado por el Programa Estatal de Investigación, Desarrollo e Innovación Orientada a los Retos de la Sociedad, del Ministerio de Industria y Competitividad del Gobierno de España.

[8] El Fondo de Gestión Social Legislativa, conocido como "barrilito" y "cofrecito", es una asignación mensual que reciben los legisladores para realizar obras sociales en su comunidad. Medicinas, alimentos, becas o materiales de construcción, entre otros, son los destinos de estas regalías de los legisladores.

[9] Auto-ubicación ideológica, Legislatura 2006-2010: PRD (5,1); PLD (6,1); PRSC (5,7), Polarización $(0,21)$ (PELA, Universidad de Salamanca)..

[10] Se repartieron 7.000 estufas de gas a nuevos beneficiarios del programa «Solidaridad» en las provincias de Dajabon, Elías Piña, Pedernales y Montecristi (Periódico Listín Diario de 14 de febrero de 2010)..

[11] Resolución 02-2010 de la JCE. Ver noticia en periódico Listín Diario del 11 de mayo en https://listindiario. com/la-republica/2010/05/11/141556/jce-ordenanbspsuspension-planes-sociales-del-14-al-17-de-mayo

[12] Palabras del candidato y ex Presidente Hipólito Mejía en el acto de conformación de la alianza con el partido MODA (Periódico HOY de 27 de febrero de 2012)..

[13] Ver noticias acerca del reparto de comida, electrodomésticos y material escolar en estas fechas en el periódico El Nacional, en http://elnacional.com.do/ administradora-del-inavi-entrega-regalos-por-motivodel-dia-de-las-madres/ y en http://enteraterd.com/page/ adn-anuncia-celebracion-semana-santa-en-guibia-coninstalacion-12-piscinas/.

[14] La población activa pasó de 3.613 .465 personas en 2006 a 4.013.328 en 2011 (CEPAL 2006-2017). Según datos de la Tesorería General de la República Dominicana, el número de cotizantes en 2006 era de 808.496 (el $15,70 \%$ de la fuerza laboral) y en 2012 de 1,291.137 (el $27,60 \%$ de la fuerza laboral). . 


\section{REFERENCIAS BibLIOGRÁfiCAS}

Abramo, L. 2016. La protección social ante la matriz de desigualdad social en América Latina. Santiago de Chile: CEPAL.

Acemoglu, D. y J. Robinson. 2012. Why nations fail. The origins of power, prosperity and poverty. New York: Crown Publisher.

Adelantado, J. y E. Scherer. 2008. "Desigualdad, democracia y políticas sociales focalizadas en América Latina". Revista Chilena de Administración Pública 11: 117-134.

ADESS. 2012. Administradora de Subsidios Sociales. Gobierno de la República Dominicana. Estadísticas. Consulta 23 de diciembre 2017 http://www.adess.gob.do/subsidios-sociales/graficos-y-estadisticas/

Alesina, A., S. Danninger. y M. Rostagno. 1999. "Redistribution through Public Employment: The Case of Italy". NBER Working Paper 7387. https://doi.org/10.3386/w7387

Allen, N. 2015. "Clientelism and the personal vote in Indonesia". Electoral Studies 37: 73-85. https://doi. org/10.1016/j.electstud.2014.10.005

Amarante, V. y J. P. Jiménez. 2016. "Distribución del ingreso e imposición a las altas rentas en América Latina". Cuadernos de Economía 35: 39-73. https://doi. org/10.15446/cuad.econ.v35n67.52441

Andrenacci, L. 2009. "Notas acerca de la política asistencial en América Latina”. Revista Cátedra Paralela 6: 7-30.

Ansolabehere, S. y J. Snyder. 2003. "Party control of state government and the distribution of public expenditures". Scandinavian Journal of Economics 108 (4): 547-569. https://doi.org/10.1111/j.1467-9442.2006.00470.x

Antía, F. 2013. “¿Hacia una moderación de la dualización? Reformas recientes de las políticas sociales en Chile y Uruguay". Pp. 267-294 en Instituições, atores estratégicos e Desenvolvimento: América Latina frente ao século XXI, editado por A. Del Rio y F. Gaitán. Rio de Janeiro: Ponteiro.

Arza, C. 2013. "Basic pensions in Latin America. Toward a rights-based policy?". Pp. 87-112 en Citizen's income and welfare regimes in Latin America: from cash transfers to rights. New York: Palgrave Macmillan.

Báez, C.J. 2011. Partidos políticos y movimiento popular en la República Dominicana. Santo Domingo: Betania.

Baraibar, X. 2015. "Lo que nos dejó el tiempo. Política asistencial e integración social”. Revista de Políticas Públicas 19: 133-144. https://doi.org/10.18764/2178-2865. v19n1p133-144

Benito, A.B. 2011. "La marea morada: elecciones congresuales y municipales de 2010 en la República Dominicana". Pp. 379-411 en América Latina: Política y Elecciones en el Bicentenario (2009-2010), editado por M. Alcántara y L. Tagina. Madrid: CEPC.

Benito, A.B. 2017. "El diputado conseguidor. Representación política particularista en el Congreso de la República Dominicana, 1998-2010". Revista Española de Ciencia Política 44 (Julio): 151-179. https://doi.org/10.21308/ recp.44.06

Benito, A.B. 2018. "República Dominicana 2016: Gobierno repartido de Unidad Nacional". Pp. 405-426 en Elecciones y partidos en América Latina en el cambio de ciclo, editado por M. Alcántara, D. Buquet y M. Tagina. Madrid: CIS
Berry, C., B. Burden y W. Howell. 2010. "The President and the Distribution of Federal Spending". American Political Science Review 104(4): 783-799. https://doi. org/10.1017/S0003055410000377

BID. 2012. Banco Interamericano de Desarrollo. Estadísticas. Consulta 19 de marzo 2016 (http://www.iadb.org/).

Calle, L. De La. 2005. "Carreteras y votos: el PSOE y las políticas territoriales de construcción de coaliciones de apoyo, 1982-1996". Revista de Investigaciones Políticas y Sociológicas 4(1): 65-96.

Calvo, E. y M. Murillo. 2004. "Who Delivers? Partisan Clients in the Argentine Electoral Market". American Journal of Political Science 48(4): 742-757. https://doi. org/10.1111/j.0092-5853.2004.00099.x

Carlin, R., M. Singer y E. Zechmeister. 2015. "Introduction to the Latin American voter". Pp. 1-27 en The Latin American voter, pursuing representation and accountability in challenging context, editado por R. Carlin, M. Singer y E. Zechmeister. Ann Arbor: University o Michigian Press.

Carrasco, H., E. García, S. Parodi y M. Vásquez. 2016. ¿Cómo se redistribuyen los recursos públicos en República Dominicana? Washington: BID. https://doi. org/10.18235/0000378

Carrera, M. y R. Muñoz. 2009. "El reto de la pobreza y la desigualdad en América Latina”. Sistema (208-209): 73-95.

Cecchini, S. y A. Madariaga. 2011. Programas de transferencias condicionadas. Balance de la experiencia reciente en América Latina y El Caribe. Cuadernos de la CEPAL, 95. Santiago de Chile.

CEPAL. 2006-2017. Comisión Económica para América Latina y El Caribe. Estadísticas. Consulta 5 de mayo 2016 (http://estadisticas.cepal.org/).

CEPAL. 2012. Panorama social de América Latina. Santiago de Chile: ONU.

Cibecchi, C. 2008. "Programas de transferencia de ingresos. ¿Más condicionalidades y menos derechos para las madres pobres? Un análisis en base a tres experiencias en América Latina". Revista Aportes Andinos 21: 1-16.

De La O, A. 2013. "Do Conditiontal Cash Transfers Effect Electoral Behavior? Evidence from a Randomized Experiment in Mexico". American Journal of Political Science 57(1): 1-14. https://doi.org/10.1111/j.15405907.2012.00617.x

DIGEPRES. 2017. Dirección General de Presupuesto de la República Dominicana. Estadísticas presupuestarias. Consulta 7 enero 2017 (http://www.digepres.gob.do/).

Dixit, A. y J. Londregan. 1996. "The determinants of Success of Special Interests in Redistributive Politics". The Journal of Politics 58(4): 1132-1155. https://doi. org/10.2307/2960152

Dowding, K. 1994. "The compatibility of behaviouralism, rational choice and new institutionalism". Journal of Theoretical Politics 6: 105-117. https://doi. org/10.1177/0951692894006001005

Espinal, R., J. Morgan y M. Seligson. 2013. Cultura Política de la Democracia en República Dominicana y Las Américas. Hacia la igualdad de oportunidades. LAPOP, Vanderbilt University. 
Faxas, L. 2007. El mito roto: Sistema político y movimiento popular en la República Dominicana, 1961-1990. México: Siglo XXI, FUNGLODE y FLACSO.

Ferraro, A. 2009. Reinventando el Estado. Por una administración pública democrática y profesional en Iberoamérica. Madrid: INAP.

Ferreira, F., J. Messina, J. Rigolini, L. F. López, M. A. Lugo y R. Vakis. 2013. Panorámica General: La movilidad económica y el crecimiento de la clase media en América Latina. Washington: Banco Mundial.

Filgueira, F. 1998. "El nuevo modelo de prestaciones sociales en América Latina: residualismo y ciudadanía estratificada". Ciudadanía y Política Social 1: 71-116.

Fraser, N. 2012. Can society be commodities all the way down? Polanyian reflectionson capitalis crisis". Working Papers Series 18, París: Fondation Maison des Sciences de l'Homme and College deÉstudes Mondiales.

Gambetta, D. 1988. Trust: Making and breaking cooperative relations. Oxford and New York: Basil Blackwell.

Gilbert, N. 2004. The transformation of the Welfare State. The silent surrender of public responsibility. Oxford: Oxford University Press.

Gough, I. y G. Therborn. 2010. "The global future of Welfare States". Pp. 703-720 en The Oxford Handbook of the Welfare State, editado por F. Castles, S. Leibfried, J. Lewis, H. Obinger y C. Pierson. Oxford: Oxford University Press. https://doi.org/10.1093/oxfordhb/9780199579396.003.0048

Hawkins, K. 2010. Venezuela's Chavismo and Populism in Comparative Perspective. New York: Cambridge University Press. https://doi.org/10.1017/ CBO9780511730245

Hevia de la Jara, F. 2010. "Uso político de programas sociales y nuevos intermediarios institucionales: el Programa Progresa/Oportunidades en el sur de Veracruz". Desacatos 34: 119-132.

Huber, E. y J. Stephens. 2012. Democracy and the left: social policy and inequality in Latin America. Chicago: University of Chicago Press. https://doi.org/10.7208/ chicago/9780226356556.001.0001

Jacobs, K. y N. Spierings.2010. "District magnitude and voter turnout a multi-level analysis of self-reported voting in the 32 Dominican Republic districts". Electoral Studies 29 (4): 704-718. https://doi.org/10.1016/j.electstud.2010.07.007

Kitschelt, H. y D. Kselman (eds.). 2011. "Organizational Extensiveness and Political Clientelism: The Formal and Informal 'Ties that Bind'”. Workshop presented on Democratic Accountability Strategies May 18-19, Duke University, Durham NC.

Kitschelt, H. y S. Wilkinson. 2007. Patrons, Clients and Policies. Cambridge: Cambridge University Press. https:// doi.org/10.1017/CBO9780511585869

Kramon, E. y D. Posner. 2013. "Who Benefits from Distributive Politics? How the outcome one studies affects the answer one gets". Perspectives on Politics 11(2): 461474. https://doi.org/10.1017/S1537592713001035

LAPOP. 2010. The Americas Barometer by the Latin American Public Opinion Project. Consulta 30 junio de 2017 (http://www.lapopsurveys.org)

LAPOP. 2012. The Political Culture of Democracy in the Americas 2012: Towards Equality of Opportunity. Nashville: Vanderbilt University.
Lavinas, L. 2012. "Desafíos de la política social de Brasil. Cómo mantener el crecimiento económico con inclusión social". Revista Ciencias Sociales 135-136: 199213.

Lavinas, L. 2013. "Latin America anti-poverty schemes instead of social protection". Working Paper Series 51, Berlin: International Research Network on Interdependent Inequalities in Latin America.

Levitsky, S. 2007. "From populism to clientelism? The transformation of labor-based party linkages in Latin American”. Pp. 206-226 en Patrons, Clients and Policies. Patterns of Democratic Accountability and Political Competition, editado por H. Kitschelt y S. Wilkinson. Cambridge: Cambridge University Press.

Levitt, S. y J. Snyder. 1995. "Political Parties and the Distribution of Federal Outlays". American Journal of Political Science 39 (4): 958-980. https://doi. org/10.2307/2111665

Lima Lucio, M. de. 2017. "Desarrollo humano, acción pública y transversalidad de los instrumentos de gestión. Una mirada al programa Bolsa Familia". Working Paper. Madrid: CEPC.

Maiz, R. 2005. "El clientelismo de partido y la corrupción política”. Pp. 363-390 en Instituciones y Procesos Políticos. Madrid: CIS.

Magaloni, B. 2006. Voting for Autocracy: Hegemonic Party Survival and its Demise in Mexico. Cambridge: Cambridge University Press. https://doi.org/10.1017/ CBO9780511510274

MAP. 2012. Ministerio de Administración Pública de la República Dominicana. Estadísticas SASP. Consulta el 13 de diciembre 2013 (https://map.gob.do/)

Mares, I. y M. Carnes. 2009. "Social Policy in Developing Countries". The Annual Review of Political Science 12: 93-113. https://doi.org/10.1146/annurev.polisci.12.071207.093504

Martínez, J. 2007. Regímenes de bienestar en América Latina. Madrid: Fundación Carolina.

Medina, L. y S. Stokes. 2007. "Monopoly and monotoring: an approach to political clientelism"- Pp. 68-83 en Patrons, Clients and Policies. Patterns of Democratic Accountability and Political Competitio, editado por $\mathrm{H}$. Kitschelt y S. Wilkinson. Cambridge: Cambridge University Press.

Nitcher, S. 2008. "Vote buying or tornout buying? Machine politics and the secret ballot". American Political Science Review 102 (01): 19-31. https://doi.org/10.1017/ S0003055408080106

O'Donnell, G. 1994. "Delegative Democracy". Journal of Democracy 5(1): 55-69. https://doi.org/10.1353/ jod.1994.0010

OEA. 2012. Organización de Estados Americanos. Informes Misiones de Observación Electoral. Consulta el 18 de octubre 2018 (http://www.oas.org/eomdatabase/)

OIT. 2011. Organización Internacional del Trabajo. Estadísticas. Consulta 14 de febrero 2017 (http://www.ilo.org/ global/statistics-and-databases/)

ONE. 2011. Oficina Nacional de Estadística de la República Dominicana. Consulta 19 marzo 2017 ( https://www. one.gob.do/)

Panebianco, A. 1982. Modelos de partido. Madrid: Alianza Editorial. 
PELA. 2010-2012. Proyecto Élites Parlamentarias. Manuel Alcántara (dir.) Universidad de Salamanca. (1994-2017). Consulta 23 diciembre 2017 (https://oir.org.es/pela/)

Piattoni, S.2001. Clientelism, Interests, and Democratic Representation: The European Experience in Historical and Comparative Perspective. Cambridge: Cambridge University Press. https://doi.org/10.1017/ СBO9781139175340

PNUD. 2013. Programa de la Naciones Unidas para el Desarrollo. Informe sobre Desarrollo Humano. Nueva York: PNUD.

Rico, G. y M. Torcal. 2018. "El voto y los elementos psicológicos del anclaje". Pp. 109- 136 en El votante dominicano. Ciudadanos y Elecciones en República Dominicana, editado por M. Torcal, L. Ruiz y G. Maldonado. Santo Domingo: CIDE, FUNGLODE, FLACSO.

Rocha, A. 2001. "Do Old Habits Die Hard? A Statistical Exploration of the Politicization of Progresa, Mexico's Latest Federal Poverty-Alleviation Programme, under Zedillo Administration". Journal of Latin American Studies 33: 513-538.

Rosas, G. y K. Hawkins. 2008. "Turncoats, true Believers, and Turnout: Machine Politics in the Absence of Vote monitoring", Working Paper, St. Louis: Washington University in St. Louis and Brigham Young University.

Schady, R. 2000. "The Political Economy of Expenditures by the Peruvian Social Fund 1991-1995". American Political Science Review 94 (2): 289-304. https://doi. org/10.2307/2586013

Scheiner, E. 2007. "Clientelism in Japan: the importance and limits of institutional explanations". Pp. 276-297 en Patrons, Clients and Policies. Patterns of Democratic Accountability and Political Competition, editado por $\mathrm{H}$. Kitschelt y $\mathrm{S}$. Wilkinson. Cambridge: Cambridge University Press.

Scott, J. 2001. Distributive Incidence of Social Spending in Mexico. México: CIDE

Shefner, J. 2001. "Coalitions and clientelism in Mexico". Theory and Society 30 (5): 593-628. https://doi. org/10.1023/A:1013042708058

Siavelis, P. y S. Morgenstern. 2008. Pathways to power: political recruitment and candidate selection in Latin America. Penn State University Press.

Singer, M. y R. Carlin. 2013. "Context counts: the election cycle, development, and the nature of economic voting". The Journal of Politics 75: 730-742. https://doi. org/10.1017/S0022381613000467

Stampini, M. y L. Tornarolli. 2012. "The growth of conditional cash transfers in Latin America and the Caribbean: did they go too far?". Policy Brief, 185. Washington: BID.

Stokes, S. 2005. "Perverse Accountability. A Formal Model of Machine Politics with Evidence from Argentina". American Political Science Review 99 (3): 315-325. https:// doi.org/10.1017/S0003055405051683

Stokes, S., T. Dunning, M. Nazareno y V. Brusco. 2013. Brokers, Voters, and Clientelism. The Puzzle of Distributive Politics. Cambridge: Cambridge University Press. https://doi.org/10.1017/CBO9781107324909

Suárez, N. 2013. Primer Informe de Monitoreo Aplicación de la Ley de Función Pública No. 41 de 2008 y su Reglamento. Santo Domingo: Participación Ciudadana.

Takahashi, Y. 2007. "The Political Economy of Targeted Poverty Alleviation: Distributive Politics, Electoral Cycles, and Progresa-Oportunidades in Mexico". Ponencia presentada en el Latin American Studies Association, International Congress, 2007, 5-8 septiembre, Montreal.

Therborn, G. 2011. "Inequalities in Latin America. From the enlightenment to the $21^{\text {st }}$ century". Working Paper Series, 1. Berlin: International Research Network on Interdependent Inequalities in Latin America.

Torcal, M., G. Maldonado y L. Rodríguez. 2018. El votante dominicano. Ciudadanos y Elecciones en República Dominicana. Santo Domingo: CIDE, FUNGLODE, FLACSO

Weitz-Shapiro, R. 2006. "Partisanship protest. The Politics of Workfare Distribution in Argentina". Latin American Research Review 41(3): 122-147. https://doi.org/10.1353/ lar.2006.0051

Weitz-Shapiro, R. 2014. Curbing Clientelism in Argentina. Politics, Poverty, and Social Policy. Cambridge: Cambridge University Press. https://doi.org/10.1017/ CBO9781139683579

Weyland, K. 2013. "Latin America's Authoritarian Drift. The Threat from the Populist Left". Journal of Democracy 24 (3): 18-32. https://doi.org/10.1353/jod.2013.0045

ANA BELÉN BENITO SÁNCHEZ es Investigadora postdoctoral del Programa García Pelayo del Centro de Estudios Políticos y Constitucionales (CEPC). Doctora en Ciencia Política por la Universidad de Salamanca. Ha sido investigadora en la Universidad de Puerto Rico (2002) y en el Instituto de Iberoamérica-USAL (2008) e investigadora visitante en la Facultad Latinoamericana de Ciencias Sociales (FLACSO-RD), en el Programa de Cooperación Científica del MAEC-AECID (2009-2011) y de la Fundación Carolina (2011). Sus trabajos sobre los sistemas de partidos han sido publicados en las revistas Política y Gobierno, Revista Española de Ciencia Política, Latin American Perspectives, Revista de Ciencia Política y América Latina Hoy. 